\title{
Correction to: Transient Sub-cellular Localization and In Vivo Protein-Protein Interaction Study of Multiple Abiotic Stress Responsive AtelF4A-III and AtALY4 Proteins in Arabidopsis thaliana
}

\author{
Indrani Baruah ${ }^{1,2} \cdot$ Geetanjali Baruah $^{3} \cdot$ Jagajjit Sahu $^{4} \cdot$ Dhanawantari L. Singha $^{1} \cdot$ Hariprasanna Dekaboruah $^{1,2}$. \\ Natarajan Velmurugan ${ }^{2,5} \cdot$ Channakeshavaiah Chikkaputtaiah $^{1,2}$ \\ Published online: 8 March 2021 \\ (c) Springer Science+Business Media, LLC, part of Springer Nature 2021
}

\section{Correction to: Plant Mol Biol Rep (2020) 38:538-553 https://doi.org/10.1007/s11105-020-01219-w}

The original version of this article unfortunately contained some mistakes.

The affiliation 2 in the published article was Academy of Scientific and Innovative Research (AcSIR), CSIR-NEIST Campus, Jorhat, Assam 785006, India.

Indrani Baruah, who is a first author of the above article is required to change her affiliation as Academy of Scientific and Innovative Research (AcSIR), Ghaziabad- 201 002, Uttar Pradesh, India.

Laboratory-Itanagar, Naharlagun, Arunachal Pradesh 791110, India
Publisher's Note Springer Nature remains neutral with regard to jurisdictional claims in published maps and institutional affiliations.

The original article can be found online at https://doi.org/10.1007/ s11105-020-01219-w.

Channakeshavaiah Chikkaputtaiah

channakeshav@neist.res.in

1 Biotechnology Group, Biological Sciences and Technology

Division, CSIR-NEIST, Jorhat, Assam 785006, India

2 Academy of Scientific and Innovative Research (AcSIR), Ghaziabad- 201 002, Uttar Pradesh, India

3 Environment Division, Assam Science Technology and Environment Council (ASTEC), Bigyan Bhawan, Guwahati, Assam 781005, India

4 DBT-NECAB, DBT-North East Centre for Agricultural Biotechnology, Assam Agriculture University, Jorhat, Assam 785013, India

5 Biological Sciences and Technology Division, CSIR-NEIST Branch Lab Itanagar, Naharlagun, Arunachal Pradesh 791110, India, Jorhat, Assam, India 